\title{
Simplicity, one-shot hypotheses and paleobiological explanation
}

\author{
Adrian Currie ${ }^{1}$
}

Received: 14 November 2018 / Accepted: 5 March 2019 / Published online: 11 March 2019 (C) The Author(s) 2019

\begin{abstract}
Paleobiologists (and other historical scientists) often provide simple narratives to explain complex, contingent episodes. These narratives are sometimes 'one-shot hypotheses' which are treated as being mutually exclusive with other possible explanations of the target episode, and are thus extended to accommodate as much about the episode as possible. I argue that a provisional preference for such hypotheses provides two kinds of productive scaffolding. First, they generate 'hypothetical differencemakers': one-shot hypotheses highlight and isolate empirically tractable dependencies between variables. Second, investigations of hypothetical difference-makers provision explanatory resources, the 'raw materials' for constructing more complex-and likely more adequate-explanations. Provisional preferences for simple, one-shot hypotheses in historical science, then, is defeasibly justified on indirect—strategic_-grounds. My argument is made in reference to recent developments regarding the $\mathrm{K}-\mathrm{Pg}$ extinction.
\end{abstract}

Keywords Explanation · Historical science $\cdot$ Mass extinction · Paleobiology · Pursuit · Simplicity

\section{Introduction}

Scientific assumptions, practices and preferences are often vindicated (or damned) in terms of well-grounded expectations about how the world is. ${ }^{1}$ I want to encourage a richer route to the epistemology of scientific preferences via consideration of

\footnotetext{
${ }^{1}$ I don't take myself to mean anything technical, weighty or special by 'preference' or 'assumption' here: some features of scientific practice are common, and I'll take these to broadly fall into those categories. See Currie (2018a) for a discussion of this kind of defense of scientific practice in an ecological context.

Adrian Currie

a.currie@exeter.ac.uk

1 University of Exeter, Exeter, England, UK
} 
a type of explanation found in paleobiology (and historical science more generally): 'one-shot hypotheses'.

Hominid brain size evolution was driven by increased sociality (Dunbar 2009); sauropod gigantism evolved in response to high atmospheric oxygen (Berner et al. 2007); feathers evolved for insulation (Prum 1999). Each of these explanations takes a complex history and accounts for it with a single factor. Indeed, the explanation is taken to be the explanation; that is, mutually exclusive with other hypotheses regarding the target event. These are one shot hypotheses. Such explanations are not all paleobiologists are interested in, but considering the messiness of the biological past their frequency is surprising. ${ }^{2}$ Why would paleobiologists over-extend simple hypotheses so regularly?

I'm going to argue that one-shot hypotheses potentially play important roles in shaping paleobiological enquiry in fruitful, productive ways. They can aid understanding of otherwise baffling events; they enable investigation of complex causal factors and facilitate their integration. I'll emphasize how one-shot hypotheses-and simple narratives in paleobiology more generally - can provide these benefits even when we should expect them to be false. This, I think, is an example of the productive speculation characteristic of the strategies historical scientists adopt (Currie 2018b; Currie \& Sterelny 2017). Note that the epistemic defence I provide is provisional and defeasible. My argument is consistent with preferences for simplicity or one-shot hypotheses being on balance epistemologically harmful. No doubt psychological biases towards simplicity might mislead and problematically constrain scientific investigation. But to ascertain the pursuitability of scientific practices, we must weigh the good against the bad (Nyrup 2018), and in this paper I'm articulating the good.

This point-that I'm establishing the positive epistemic value one-shot hypotheses could have-heads off a methodological worry. My focus is on a small set of hypotheses, and I picked them because they successfully illustrate the value I think one-shot hypotheses can have. But are these cases representative? There are also one-shot hypotheses which have not led to the kinds of benefits I identify. I'm not here making an inductive case to say that one-shot hypotheses always — or even frequently - have such values. Rather, I'm arguing that in the best case, these are the epistemic dividends they bring (see Currie 2015a for a general defence of the use of case studies in philosophy of science). When considering a particular hypothesis, whether or not it brings such benefits plays an important part in establishing its pursuitworthiness or otherwise, but it does not exhaust the features that matter.

I'll make my argument in light of some of the most famous one-shot hypotheses in paleobiology: that an extraterrestrial impact, or massive volcanism, are to blame for the Cretaceous-Paleogene (K-Pg) extinction and subsequent mammalian radiation which ended the Mesozoic and ushered in the Cenozoic. ${ }^{3}$ I'll start with

\footnotetext{
2 My epistemic analysis doesn't turn on the actual frequency of the use of one-shot hypotheses, however.

3 The K-Pg event is something of a touchstone in philosophical discussion of historical reconstruction. Carol Cleland makes prominent use of it in defending her 'smoking gun' account of historical method (2002), and to illustrate the inexactness of historical hypotheses (2013). Forber and Griffith (2011) appeal to it in defending their consilience-driven account. My treatment differs in part because the science has moved on, in part because we have different focuses. I don't think the philosophical points in
} 
some conceptual housekeeping: I'll identify the kind of simplicity I'm interested in and clarify the kind of argument I'll be making. I'll then delve into the case-studies to highlight the relevant features of one-shot hypotheses. With that in place, I'll argue that one-shot hypotheses sometimes play an epistemically productive role in paleobiology.

\section{Conceptual housekeeping}

In this section I'll first characterize a hitherto unnoticed kind of scientific simplicity - 'narrative simplicity' — second distinguish between two ways of vindicating a scientific practice, preference or assumption.

\subsection{Narrative simplicity}

While philosophical discussion of simplicity has focused on theoretical and ontological simplicity, I'll introduce a further notion: narrative simplicity ${ }^{4}$ which builds on my previous distinction between simple and complex narratives (Currie 2014). With this in place I can zero-in on 'one-shot' hypotheses.

Theoretical simplicity can be understood as the number of variables and posits in a theoretical structure; ontological simplicity can be understood as the number of kinds, or the numbers of individuals, in a given ontology (i.e., Nolan 1997). The two might be closely related: if theories are representations of the world, then an accurate theory will be similarly simple (or complex) as the aspect of the world that theory represents (although accuracy is not the only, or main, criteria for a successful representation, Potochnik 2017). Theoretical simplicity is mostly discussed in the philosophy of science in the context of debates about realism (e.g., Lipton 1993). Given that empirical evidence underdetermines how we should interpret even our most successful theories, perhaps appeal to super-empirical virtues ground arguments for the truth of one interpretation or theory over another (Churchland 1982). Theoretical simplicity is amongst the grab-bag of super-empirical virtues (elegance, explanatory power, unification, etc.) which might do this inferential work. ${ }^{5}$ In metaphysics, ontological simplicity is often used as a criteria for judging between various systems (as in Occam's razor for instance). For example, David Lewis appeals to

Footnote 3 (continued)

those papers or mine necessarily hinge on the details of how the science turns out (Currie 2015a; Turner 2016).

${ }^{4}$ Bunge (1962) argues against the role of simplicity in philosophical analysis because of the sheer number of ways in which it might be understood. My claim here is simply that narrative simplicity differs from ontological and theoretical simplicity and that it appears to play an important role in shaping palaeontological investigation: I think it coheres with Bunge's claim.

${ }^{5}$ For some possible lists of such virtues, see Kuhn (1977), Thagard (1978) and Goodman (1968). 
the (supposed) ontological simplicity of concreteness about possible worlds (Lewis 1986). ${ }^{6}$

Narrative simplicity is different. The notion applies to a particular narrative, that is, an explanation of a particular as opposed to a general representation of how the world is. We can understand narrative simplicity as the sum of two features. The first is related to theoretical simplicity; the second relates to the simplicity of the narrative itself. Let's turn to ecology for a toy example of how this could go.

Here is a very simple ecological growth model:

$$
\Delta N=B-D+I-E
$$

where $\Delta N$ is the change in a population over time (assuming change is steady), $B$ is birth rate, $D$ death rate, $I$ immigration and $E$ emigration. Take the equation as a theory of population growth in the absence of resource constraints: it describes a modal space relevant to population change under those conditions. That modal space includes: circumstances where birth and immigration outweigh death and emigration, thus populations grow exponentially; circumstances where death and emigration outweigh birth and immigration, thus populations plummet; circumstances where things are balanced and the population remains steady. Consider the application of the theory to a particular instance. Imagine a recently introduced population on an island exhibits exponential population growth. We might explain this by situating the case within the modal space delineated by the model. Because births outweigh deaths, and the island is isolated, forbidding immigration or emigration, we should expect population numbers to increase exponentially.

So, we can understand a theory or model as describing a possibility space. Some narratives situate an instance within such possibility spaces, as we just saw in our toy case. I call such narratives embedded (Currie 2014). In this context, narrative simplicity is parasitic on theoretical simplicity. If narratives involve situating instances in the possibility spaces theories describe, then the more complex a theory, the more complex the narrative. Our toy case is embedded in a very simple theory, and so is a derivatively simple narrative as well. Distinguish between two related features of embeddedness. First, an embedded explanation might be applied to one instance of a set of actual events: if the $\mathrm{K}-\mathrm{Pg}$ and the end-Permian extinction events were similarly triggered by mass volcanism, then we can treat them as tokens embedded in a common type. Second, explanations are situated within a possibility space delineated by a theory. Our theory of volcano-driven mass extinction accounts for the $\mathrm{K}-\mathrm{Pg}$ extinction (if it does) by citing a set of conditions for the phenomena to occur and demonstrating that the case at hand meets those conditions (I consider this latter feature to be equivalent to treating the target as an instance of a set of possible events). The latter feature is, I think, primary, but for epistemic reasons the two are

\footnotetext{
${ }^{6}$ On my reading, Lewis argues that his inflation of world-tokens is less costly than the conceptual inflation that he thinks ersatz realists need. He thinks adding more types of objects is a significant ontological cost, but that introducing more tokens is not.

7 'Embedded' is perhaps misleading: by the term I mean the narrative is situated within a theory or model, as opposed to, say, being embedded in the structure of the world, or in many lines of evidence.
} 
connected: without common instances we are unlikely to have sufficient understanding to construct the embedding theory. ${ }^{8}$

However, some narratives do not situate their subjects within a single possibility space or theory. Instead, they describe complex sequences of change across time. Keeping with our toy example, say that our introduced population begins to oscillate at regular time intervals. As opposed to continually increasing, the population increases for a period, and then starts to decrease; this pattern is then repeated. We discover that this has occurred due to the introduction of a predator. We can understand the new pattern using theories of predator-prey interaction, thus switching the space in which we situate our narrative. Where previously a simple growth equation would do, we now utilize a coupled differential equation. To explain the overall pattern in the population, from exponential increase to oscillations, we need to do more than situate the instance within a modal space, but explain both shifts across that space, and changes to the space itself. Narrative complexity, then, is not parasitic on theoretical complexity alone, we need to also consider what I've called detail. ${ }^{9}$

A natural way of understanding detail is in terms of 'difference-makers'. Difference-making is a popular way of understanding causation in scientific contexts. Following Woodward (2005), some variable is a difference-maker for some effect just in case, given some ideal intervention on that variable (ideal insofar as (1) we hold everything fixed downstream of the variable and (2) the intervention only has to be physically possible), the effect changes. The impact hypothesis is a rather stark example. Consider the counterfactual where everything on Earth 65.5 million years ago is kept as is, but the bolide's trajectory is shifted such that it misses Earth, thus there is no impact. In this counterfactual, according to the hypothesis, there is no $\mathrm{K}-\mathrm{Pg}$ extinction. As we increase the number of difference-makers cited in an explanation, so we increase the narrative's detail. In our original toy narrative, we cited the lack of resource constraints, the island's isolation, and the birth/death rate of the population. With the introduction of predators, we add difference-makers relating to the dynamic of the new population, as well as their interactions with the original one (predation rate, for instance). ${ }^{10}$ Further, along a narrative a single difference-maker might be altered in different ways. So even if a narrative is embedded in a simple theory, it may be highly detailed if a cluster of changes to the theory's variables are required.

Following Currie (2014), then, we can understand narrative simplicity and complexity along two dimensions. First, embeddedness, that is, the extent to which the narrative is situated within a theory or model; second, detail, that is, the number of

\footnotetext{
${ }^{8}$ Note that I don't necessarily take being embedded as a required feature of a narrative explanation: I am open to there being cases where narratives explain without appeal to theories.

${ }^{9}$ One can situate both parts of the narrative within a predator-prey model by setting predator population to zero in the initial stage. However, there are narratives where it is difficult to imagine them being embedded in a single model: consider my discussion of Sauropod gigantism, for instance (Currie 2014, 2018b).

${ }^{10}$ Embeddedness and detail are often coupled, as increases in difference-makers tend to undermine embeddedness-although this connection is far from logically necessary.
} 
difference-makers cited in the narrative. One-shot hypotheses are a subset of simple narratives.

We can understand one-shot hypotheses as being (1) simple narratives which are (2) treated as being mutually exclusive with other putative hypotheses. This mutual exclusivity motivates extension: scientists attempt to offer as full an explanation of the event as possible according to a few difference-makers against a 'business-asusual' backdrop. We might insist, for example, that the introduction of predators alone explains the change in dynamics of our toy population, and further insist that it is not due to, say, the population reaching the island's carrying capacity. This combination of simplicity, mutual-exclusivity and extension generates the indirect epistemic benefits which underwrite my partial defence of one-shot hypotheses.

\subsection{Epistemic value}

Insofar as paleobiologists prefer one-shot hypotheses, is that preference justified? I want to answer with a qualified, highly context-sensitive 'yes'. I happen to not think that we should expect narrative simplicity, or one-shot hypotheses, to reflect the structure of the world: that is, we shouldn't expect macroevolutionary targets to be simple, and so shouldn't take an explanation's being simple as reason to think it likely. I do want to argue, however, that there is defeasible epistemic justification for the practice of provisionally preferring one-shot hypotheses. In this section, I'll sketch a distinction which underwrites this claim.

Contrast two ways of vindicating a scientific practice. The first claims the practice is knowledge-tracking; the second claims the practice is knowledge-promoting. In the former case, we argue that the practice generates knowledge directly: it has features which either map onto the phenomenon at hand, or are in some way crucial for the knowers to know that phenomenon. Knowledge-tracking, then, turns on ontological features of the target or epistemic features of the knower. Simplicity is knowledge-tracking if the world is simple, or if simplicity is critical for our achieving knowledge. Empirical adaptationists, for example, think that natural selection is a major cause of organismal form, and so we should expect adaptive explanations to be true, and thus knowledge-tracking. Explanatory adaptationists take natural selection to answer one of the big questions about the living world-its apparent design - and so also think it is knowledge-tracking, but for reasons more to do with us as knowers than with the structure of the world (Godfrey-Smith 2001).

Second, we might argue that the practice is knowledge-promoting: that is, the practice indirectly increases the likelihood that some epistemic gains will be made. Here, whether the practice's features map onto the target or is required for some epistemic achievement is irrelevant: rather, adopting the practice makes it more likely that knowledge will be had. Methodological adaptationists don't think natural selection is necessarily so powerful in shaping life, but argue that starting with 
adaptationist hypotheses is a productive way of proceeding (Godfrey-Smith 2001). ${ }^{11}$ If simplicity is knowledge-promoting, then assuming or preferring simple hypotheses will, in some contexts, direct research in productive ways.

We can understand the first kind of vindication as an appeal to epistemic ends: the practice directly targets epistemic aims-in-themselves; the second appeals to strategic goods: the practice is instrumentally valuable. Examples of epistemic ends might be accuracy, empirical adequacy, explanatory power, truth and understanding. Examples of strategic goods might be diversity, quantification (Steel 2010), or openness. Strategic goods are strategic because they indirectly promote epistemic ends. ${ }^{12}$ I'll use knowledge-tracking and being an epistemic end; and knowledge-promoting and being a strategic good, interchangeably. Moreover, I don't think strategic goods being strategic precludes them from being properly-speaking epistemic. The point of the distinction is to extend the space of epistemology to include knowledge-promoting features.

Note that an epistemic defence of some practice might include both epistemic ends and strategic goods. In section four I'll argue that simple narratives provide epistemic ends in virtue of being necessary for some kinds of understanding. In section five I'll appeal to strategic goods: simple narratives are knowledge-promoting. Note the assumed epistemic pluralism: scientists are not after truth alone, but a range of achievements: interventions, understanding of varying types, new phenomena, and so forth. I don't want to commit to a particular list of goods, but am happy so long as we admit some set of properly-speaking epistemic goods that go beyond truth. As we'll see, this will be crucial in considering the kinds of epistemic value narrative simplicity might possess. And again, I take the distinction between knowledge-tracking and knowledge-promoting to extend the traditional boundaries of epistemology: I think knowledge-promoting features ought to be considered properly-speaking epistemic features (Steel 2010).

\section{Big rocks and big volcanos}

I've lain down two pieces of conceptual machinery. First, narrative simplicity. A narrative is simple to the extent to which it is (1) embedded in a simple theory; (2) is low detail, containing minimal difference-makers. I've further characterised a oneshot hypothesis as a hypothesis which takes a simple narrative to be mutually exclusive with others. It is represented as the explanation of an event. Second, a scientific practice, assumption or preference can be defended in virtue of being knowledgetracking or knowledge-promoting. The former directly provides epistemic ends, the other has strategic value: promoting knowledge indirectly. Before moving to my

\footnotetext{
11 I am not here committed to saying that adaptationist hypotheses are defensible on the same grounds I defend for one-shot hypotheses, although they may well be (and indeed adaptationist hypotheses are often one-shots, although I'm unsure of their productivity).

12 Thanks to Rune Nyrup for the epistemic ends/strategic good terms.
} 
defence of one-shot hypotheses let's consider a case-study: explanations of the K-Pg extinction.

In addition to distinguishing between simple and complex narratives, I have previously argued that historical science exhibits a progressive pattern (Currie 2014). First, a series of simple narratives are generated. Second, these are explored and tested against the historical record, some being discarded. Third, surviving narratives are woven together into complex narratives. ${ }^{13}$ As we'll see, this is true of work on the $\mathrm{K}-\mathrm{Pg}$ extinction. One way of understanding the question I want to tackle is: given the shift from simple to complex, what value do the simple narratives have in the first place? Why not go straight to complex ones? In answering, I'll focus on two one-shot hypotheses. According to the impact hypothesis the $\mathrm{K}-\mathrm{Pg}$ mass extinction was triggered by a massive extra-terrestrial impact; according to the volcanism hypothesis massive volcanic activity takes the blame. A caveat: even if the explanations are simple in my sense, the evidential situation is often bewilderingly complex. My presentation here, then, only focuses on evidence where necessary. I'm interested in the form of the explanatory narratives and undoubtedly how the narratives develop is in concert with empirical findings. Regardless, my presentation will necessarily be selective. It's also worth noting that my presentation doesn't turn on paleobiologists in fact taking the simple narratives to be mutually exclusive-they might not believe their one-shot hypotheses-what matters for my purposes is that they are treated as such.

According to the impact hypothesis, an extra-terrestrial impact was both the trigger, and takes the majority of the causal blame, for the mass extinction dividing the Mesozoic and the Cenozoic. The hypothesis emerged in the early 1980s in a crowded marketplace of simple narratives (Alvarez et al. 1980). The basic structure of the hypothesis links the impact event to a scenario plausibly leading to a mass die-off. In addition to the immediate effect of the impact itself, downstream consequences such as a long 'winter' causing mass loss of vegetation and acid rain (making the ocean inhospitable) are a standard part of the story. Evidentially speaking, scientists work to establish (1) a correlation between the timing of the extinction and the impact; (2) trends in biodiversity leading up to the impact event; (3) the effects of the impact and their connection with the occurrence of mass extinctions.

Perhaps the most stark, and relatively recent, serious articulation of the impact hypothesis as a one-shot is Schulte et al. (2010), a 41 author review paper in Science. The paper is plausibly understood as attempting to establish a consensus: "The temporal match between the ejecta layer and the onset of the extinctions and the agreement of ecological patterns in the fossil record with modelled environmental perturbations (for example, darkness and cooling) lead us to conclude that the Chicxulub impact triggered the mass extinction" (1214). They also highlighted the downstream effects of the impact such as "extended darkness, global cooling, and

\footnotetext{
13 This contrasts with Cleland's view $(2002,2011)$, which takes investigation to proceed by hunting for smoking guns which distinguish between hypothetical past causes. Note that on the face of it this involves taking the hypotheses to be mutually exclusive: Cleland appears to miss the importance of the simple narratives being integrated.
} 
acid rain" (1214). The narrative is presented (and treated) as being mutually exclusive with others: Schulte et al. argue for the impact hypothesis and against competitors such as appeals to volcanism. Further, this involves extension: Schulte et al. attempt to account for as many features of the $\mathrm{K}-\mathrm{Pg}$ event as possible by appeal to the impact. As such, it is a classic one-shot hypothesis. ${ }^{14}$

A critical part of the argument connecting impact to extinction concerns establishing a reasonable temporal relationship between them. This is tricky, as the features of the impact are not perfectly distributed and biodiversity patterns in the fossil record are often noisy. A long-term source of resistance to the one-shot version of the hypothesis turned on whether the impact played a central role-wiping out thriving populations - or whether it was a final blow to already collapsing biota (Ward et al. 1991). Although a consensus has developed that biodiversity levels remained more-or-less stable up until the extinction, both the impact's timing, and whether late-Cretaceous biota were destabilized, has been questioned.

Schulte et al. (2010) is bundled with a set of response papers, most of which wrangle over various evidential features. Notably, a group of vertebrate paleobiologists complain that the account neglects non-oceanic life (Archibald et al. 2010). “... the simplistic extinction scenario presented in the Review has not stood up to the countless studies of how vertebrates and other terrestrial and marine organisms fared at the end of the Cretaceous" (973). They do not deny the impact's importance in triggering the mass extinction. Rather, they claim it is insufficient for the terrestrial and freshwater extinctions that accompanied the oceanic biodiversity collapse. Thus, they deny the sufficiency of the simple, one-shot narrative Schulte et al. accredit the impact.

The only hypothesis which has enjoyed anything like the impact hypothesis' longevity highlights the role of volcanism (Courtillot 1990). The Deccan traps in west-central India record an extraordinary period of volcanic activity in the late Cretaceous. Volcanic disruption at that scale could have similar effects as large extraterrestrial impacts: enormous quantities of ash are ejected into the atmosphere, lowering global temperature, filling the sea with acid rain and darkening the skies leading to plummeting vegetative productivity. Volcanic activity is increasingly linked to other mass extinctions, most notably the enormous end-Permian event which coincides with the forming of the Siberian traps. Notably, where those favouring the volcanic hypothesis embed it in a pattern of volcanic-driven mass extinctions (Ernst \& Youbi 2017), those favouring the impact hypothesis emphasize particularity: "Each mass extinction event should be considered relative to the record for that event, and we stress the unique aspects of the K-Pg boundary record" (Schulte et al. 2010, 975). ${ }^{15}$ Not only is it thought that mass extinctions are not generally caused by

\footnotetext{
14 One non-paradigm feature is their insistence that the $\mathrm{K}-\mathrm{Pg}$ be taken as a unique event, so although they do embed the event within a possible set of occurrences, they do not unify it with other actual events.

15 This certainly wasn't always true: the success of the impact hypothesis led to various models attempting to explain mass extinctions via extra-terrestrial impacts more generally. This doesn't seem to have worked.
} 
impacts, but also that the specific features and location of the Chicxulub impact mattered for triggering the extinction.

The volcanic hypothesis was long disregarded because Deccan volcanism began millions of years before the extinction. However, an increasingly fine-grained understanding of the record reveals the volcanism occurring over four pulses: the most violent being suggestively close to the $\mathrm{K}-\mathrm{Pg}$ extinction. Gerta Keller is a notable hold-out regarding the impact hypothesis, defending a near one-shot version of the volcanism hypothesis instead: "[a] series of at least four massive volcanic eruptions in short order formed the longest lava flows on Earth and probably caused runaway effects, particularly ocean acidification, which resulted in the carbonate crisis commonly considered to be the prime cause for the mass extinction. The Chicxulub impact played no role in this mass extinction" (Keller 2014, 29). She attempts to both undermine the temporal overlap between impact and extinction, as well as elaborating on Deccan volcanic activity.

Keller questions the timing of the impact. In particular, she worries that the apparent overlap between the impact and the extinction is due to the $\mathrm{K}-\mathrm{Pg}$ line- the geological strata marking the extinction-coming to be defined in terms of the signs of the impact. "The Chicxulub impact is assumed to have caused the mass extinction, and this belief, rather than statigraphic data, has led to a redefinition of the K-T boundary based on Chicxulub impact ejecta" $\left(2014,26\right.$, her italics). ${ }^{16}$

In both Keller's and Schulte et al's treatments, the impact and the volcanic hypotheses are treated as mutually exclusive: clashing one-shot explanations. But this is not the only way they have been conceived. Brusatte et al. (2015), argue that "...without the impact non-avian dinosaurs probably would not have completely died out" (638). However, they also emphasize how the late Cretaceous was, generally speaking, a time of major disruption: the extinction occurs "amidst a backdrop of massive volcanic eruptions, major changes in temperature and sea level, and the impact of a 10-km-wide bolide". They suggest that such disruptions could have decreased the resilience of terrestrial communities. As opposed to the impact upsetting typical background conditions, the fifteen million years leading to the extinction involved global temperature fluctuations between $8{ }^{\circ} \mathrm{C}$, sea-level shifts from roughly current levels to over $70 \mathrm{~m}$ higher, and, of course, Deccan volcanism. The bolide impact did its work on potentially less resilient biota: the big rock might have been necessary for the extinction, but it was not sufficient.

Overall, then, we can see a consensus regarding the timing and central role of the impact emerging. However, that consensus also shifts from a simple narrativeindeed, a one-shot hypothesis - to a complex one as the impact is situated within the disruptions of the late Cretaceous. It becomes unclear whether a single model can accommodate the explanation (embeddedness breaks down) as further difference-makers are implicated (detail increases). As I've argued we should expect, the

\footnotetext{
${ }^{16}$ I don't mean to either support or deny Keller's claim here-well above my paygrade. See Renne et al. (2013) for a more orthodox picture of increasingly precise measurement leading to a close association between impact and extinction.
} 
simple has become complex. Moreover, integrating the explanations requires abandoning the assumption that they are in conflict: mutual-exclusivity is jettisoned. ${ }^{17}$

So, is the apparent paleontological preference for one-shot hypotheses wrongheaded? I don't necessarily think so.

\section{Narrative simplicity as an epistemic end}

There are many ways of accounting for the assumptions and preference of scientists: the political, social and rhetorical play their role, as do more epistemic features. I'm going to focus on the latter here, but in doing so I don't take myself to be in conflict with those other kinds of explanations. First, sometimes the epistemic emerges from the social (Longino 1990); second, both epistemic and more pragmatic features can together explain practices; third, even if scientists adopt practices for non-epistemic reasons, we can still ask whether those practices are epistemically valuable.

In this epistemic frame of mind, one might be forgiven for thinking that a preference for one-shot (or otherwise simple) narratives in paleobiology involves a mistaken assumption: that the world is simple, or that we should generally expect simple narratives to be true narratives. When confronted with mass extinctions, perhaps we should expect those events to follow similar trajectories-and thus be amenable to being embedded — or to have a small set of difference-makers — thus be amenable to low-detail representation. If that were the case, then we might interpret paleobiological practice as assuming that narrative simplicity is an epistemic end, indicative of truth. This would be unfortunate. I don't think we've a general licence to expect history to be simple. It doesn't follow from this that narrative simplicity is not knowledge-tracking, however: I'll suggest that simple narratives could be a source of understanding, although not in a way amenable to one-shot hypotheses. As we'll see in Sect. 5, however, the story doesn't end there: much of the value of oneshot hypotheses, when they have value, is strategic: they are knowledge-promoting.

\subsection{Simple narratives and truth}

Can we underwrite a justification for preferring one-shot hypotheses or simple narratives by appeal to epistemic ends: their being knowledge-tracking? One approach to this asks whether an explanation which posits a one-shot explanation is likely to be true in virtue of its simplicity. I think this is a bad move.

As we've seen, discussion of simplicity in the philosophy of science is often cashed out in terms of whether the virtue (if indeed it is a virtue) is truth-tracking. That is, is a simple explanation more likely to be true than a complex one? The move is a mistake because of the flexibility of narrative explanation: depending

\footnotetext{
17 Derek Turner has pointed out to me that there are some contexts where establishing 'the' cause is more important: in legal, moral, or otherwise blame-or-credit establishing cases, perhaps. It may be that this defeasible preference is then transferred into other contexts.
} 
on how stringent we make our requirements for 'truth', being truth-tracking either becomes just about trivial, or far too difficult to achieve.

First, consider just-about-triviality. Narratives are explanatory in virtue of highlighting particular aspects of an otherwise complex world: they foreground and background various elements (Currie and Walsh 2019). It is plausible that which elements are so foregrounded and backgrounded depend crucially on context. One important element of that context is often the contrast class: an explanation does its work when it cites properties of the explanandum in virtue of which it differs from some set of otherwise similar events (Lipton 1990). Consider Schulte et al. (2010)'s insistence that we focus on the particulars of each extinction event. On that view, the $\mathrm{K}-\mathrm{Pg}$ extinction is special because of the role of an extra-terrestrial impact; in that context, we foreground the impact's role to distinguish that mass extinction from others. However, in other contexts we might be interested in similarities between mass extinctions. Schulte et al. do highlight the role of increased oceanic acidity in the K-Pg event, which was likely critical for other mass extinctions as well. Whether we ought to highlight the impact, or features downstream of it, appears to turn on features of explanatory context. It doesn't follow from this that just anything can make it into an explanation: indeed, if Keller is right, then citing the impact event at all is a mistake as it did not have any effect on the extinction. However, truth enters into the picture at the level of potential elements that could be used in an explanation, but whether I will be satisfied by a simple or complex explanation often turns on features of explanatory context. On this permissive conception, it is very easy for an explanation to be true-it just needs to cite the relevant elements given explanatory context-and so the simplicity or otherwise of a narrative doesn't affect its truth per se, but rather its salience. ${ }^{18}$

Second, consider a more stringent approach: we might insist that we take oneshot hypotheses as having direct truth values. Let's start by getting clear on the nature of one-shot hypotheses, by returning to difference-making.

Read at face-value, the impact hypothesis concerns actual rather than potential difference-makers (Waters 2007). That is to say, the explanation doesn't simply claim that one potential factor may have, or would have, made a difference (this is no how-possibly explanation). It rather says that the impact event in fact made a difference to the occurrence of the mass extinction. ${ }^{19}$ But more, it seems to claim that the impact was the major factor. To think simplicity indicates truth in this context, is to think that the thing you're trying to explain is likely to be simple in that way. That is, a preference for one-shot hypotheses appears to commit to a picture of life's history as being characteristically shaped by single difference-makers. The low-detail of the explanation, then, is justified because the world is shaped by such events. This seems extremely unlikely: I don't see why we should think the world is shaped

\footnotetext{
18 For further discussion of explanatory pluralism see Currie and Walsh (2019), Sterelny (1996) and Potochnik (2017).

19 The specific details of Waters' view only captures the impact event awkwardly, as it requires for the variable in question to in fact vary and in fact make a difference across the relevant populations. The population of $\mathrm{K}-\mathrm{Pg}$ extinction events is a population of 1 , and the occurrence of the impact does not vary (See Currie 2018b, chapter 6 for pressure on Waters' view from the perspective of historical science).
} 
by single difference-makers in that fashion. Moreover, the extension of one-shot hypotheses in particular makes them very unlikely to be true in this stringent sense.

So, to ask whether one-shot hypotheses are truth tracking (in virtue of being one-shot) we either make things too easy for ourselves by appealing to pragmatic features of explanation, or too hard by demanding that they pick out actual-and complete-difference-makers. As such, I don't think we are licensed to think they are truth-tracking. ${ }^{20}$ We may want to make a stronger argument, that in fact we have good reason to expect narratives to be complex. We could appeal to my previously identified pattern of simplicity being abandoned for complexity and make an induction, or we could appeal to the nature and contingency of history. For instance, Beatty (1995) and McConwell (2019) suggest that the contingency of life at the macro-scale should lead us to expect biological kinds to be pluralistic and heterogeneous. This doesn't in itself ground a preference for narrative complexity, but the bow between the two is perhaps not too long to be drawn. However, for my purposes such an argument is unnecessary.

I doubt there is an in-principle story to be told about whether we should expect macroevolutionary trends and events to be due to one-shot whammies or more complex, multi-faceted causes. ${ }^{21}$ There may be particular contexts where we have wellgrounded reasons for thinking simple narratives are truth-tracking, but there is no general justification of this type to be had.

\subsection{Simple narratives and understanding}

Explanations are not merely supposed to be true, but also adequate, that is, succeed in generating epistemic goods we're after-understanding for instance. I'm a pluralist about epistemic goods, and so epistemic ends needn't be tied to 'truth' alone. Here, I'll consider the relationship between simple narratives, one-shot hypotheses and understanding: I'll suggest that even if the world isn't simple, narrative simplicity might generate epistemic goods in virtue of our needs qua epistemic agents. It is important to note that, even if the arguments of this section prove inconclusive, this doesn't undermine the positive argument of the next section. That is, even if simplicity is to at least some extent truth-tracking vis-à-vis biology's past, that doesn't mean that there aren't other factors potentially vindicatory of such assumptions; and if simplicity sometimes generates understanding, that may not exhaust the preference's epistemic value.

A common thread in philosophy explains scientific simplicity as a symptom of our tendency to abstract and idealize: idealizations make tractable otherwise bewildering systems, provide the right contrasts for explanation, and so on (Weisberg 2007). With this in mind, we might argue that simple narratives, generally speaking,

\footnotetext{
${ }^{20}$ A related view, defended in Sober (1991) and endorsed in (Currie 2018b, chapter 6), is that appeals to virtues like simplicity are made in the light of local, justifying background theory. That is, we appeal to simplicity when we have some particular reason to expect it in the kind of system we're examining.

21 For discussion of multifactorial causes in a future-facing context see Liu et al. (2018), Kareiva and Carranza (2018).
} 
are epistemically valuable for generating understanding. Consider embeddedness: it is plausible that conceiving of an instance as a token of a type-situating it within a model we understand-aids our grasping of the event. Consider being low-detail: citing one or a few causal factors lowers the cognitive load. Certainly, I am better placed to grasp a simple narrative, then I am a complex one.

Of course, understanding is not independent of truth: although to understand an event I might distort it in various ways, there are limits to how far things can bend. Catherine Elgin captures this insight: she takes understanding to be dual-natured (2007, 2017). To generate understanding of something, one must grasp it-fulfil some cognitive criteria (Strevens 2013) — and one's conception of that thing must be sufficiently accurate- 'true enough'. On this approach we might say that even if the world isn't itself complex, simplicity fulfils a critical cognitive criteria: it enables us to grasp the phenomena.

On approaches like Elgin's, if we restrict our defence to epistemic ends, only simple narratives which represent the target event sufficiently well will be vindicated. And potentially some do: if the consensus on the $\mathrm{K}-\mathrm{Pg}$ extinction is correct, then although it leaves many details out, it may be that citing the impact is sufficient for my understanding the event at least in a coarse-grained way. However, such a defence, I think, is unavailable for one-shot hypotheses. This is because of their mutual-exclusivity. Appealing to idealizations in justifying simplistic assumptions is inherently pluralistic. What makes an idealization epistemically acceptable is whether it isolates the relevant features given our status as bounded epistemic agents: our cognitive capacities, explanatory interests, and so forth. And as these features of context shift so too does the adequacy of the idealization. As such, the monism implied by mutual exclusivity is erroneous. And so, even if some simple narratives are vindicated through the generation of understanding, one-shot hypotheses are not.

I think focusing on epistemic ends sells one-shot hypotheses short. I want to argue that consideration of strategic goods suggests that there are reasons to sometimes prefer one-shot hypotheses and other simple narratives even when we don't think they are true, or sufficiently accurate.

\section{One-shot hypotheses and knowledge-promotion}

Even though simple narratives are unlikely to be true, they might still be knowledgetracking insofar as they play a role in generating understanding. However, some simple narratives are unlikely to play this role, and the mutual exclusivity of one-shot hypotheses is particularly unsuited to generating understanding. But epistemic ends are not, I think, the whole story regarding the value of simplicity in narrative explanations. In this section, I want to argue that simple narratives provide strategic value: they are knowledge-promoting. That is, simple narratives-one-shots in particularmake it more likely that we'll get true rich explanations. They do this by providing two kinds of services. First, they generate 'hypothetical difference-makers'. Second, investigating hypothetical difference-makers provides 'explanatory resources' which may be integrated into more complex, sufficient, narratives. 


\subsection{Hypothetical difference-makers}

It is sometimes noted that scientific progress is scaffolded: to get somewhere, you often need to get somewhere else first. ${ }^{22}$ I think one-shot hypotheses often act as hypothetical difference-makers. Recall that Ken Waters (2007) distinguishes between actual difference-makers - variables that in fact vary and make a difference in virtue of that-and potential difference-makers that would make a difference if only they varied. Most discussion of difference-making is factive: Waters' distinction doesn't differentiate between epistemic strength, but modal properties. That is, what makes a difference-maker actual or potential is not our credence, but whether the variable actually makes a difference, or would make one. By contrast, I'm interested in an epistemic, credence-based notion. Waters tells us what it takes to be a potential or actual difference-maker; we will examine how postulating such things might shape investigation. A 'hypothetical difference-maker', then, is putative: it might turn out to be neither actual nor potential (in Waters' sense). But hypothesizing them enables their investigation: therein is the real value of one-shot hypotheses. ${ }^{23}$

One-shot hypotheses highlight a single variable against a relatively stable background. This motivates an investigative program targeting that variable's effects and-as we'll see in the next section-generates knowledge which is a precondition for understanding how that variable might interact with others. Further, their mutual exclusivity — and thus their extension-isolates that variable from others. To see hypothetical difference-makers in action, let's start with Keller's discussion of mercury proxies and volcanism.

As we saw in Sect. 3, Keller's strategy is two-pronged: arguing that the impact actually occurred significantly earlier than is usually thought; building a case for Deccan volcanism overlapping with the extinction, and playing a prominent role in it. A crucial part of this second task involves developing proxies for volcanic activity which can be associated both with the temporal spans required and perhaps distinguishing volcanic-caused environmental changes from others. An important part of the puzzle involves mercury $(\mathrm{Hg})$, an element that is both highly toxic, transportable over long distances, and long-lived. High oceanic $\mathrm{Hg}$ content has been associated with other major events which have potential links to volcanism; most strikingly the dramatic end-Permian mass extinction. $\mathrm{Hg}$, then, might be an excellent empirical route for linking Deccan volcanism to the mass extinction. However, Hg fluctuations are not only chalked up to volcanic activity: variation in organic matter sequestration (that is, the absorption of dead organisms into the sea) can also have dramatic effects. So, simply measuring $\mathrm{Hg}$ content in strata is insufficient for isolating volcanism. Font et al. (2016) develop a new statistical approach to $\mathrm{Hg}$, normalizing results against total organic carbon and phyllosilicate content. This enables them to identify which aspects of mercury fluctuation are explained by background sequestration and

\footnotetext{
22 For discussion of scaffolding in science, see Wimsatt (2007), Currie (2015b) and Walsh (2018).

23 This is related to the long-toothed distinguish between 'how possible' and 'how actual' explanations. However, on my view the credential versus factive readings of that distinction are so often conflated and confused that I'd rather avoid it.
} 
other factors, and which are likely due to volcanism. Developing the proxy involves more than figuring out how to measure $\mathrm{Hg}$ levels, but must be further tweaked to generate results relevant to the task at hand.

Font et al's technique is used to establish a mercury anomaly coinciding with the $\mathrm{K}-\mathrm{Pg}$ extinction ("two orders of magnitude higher in the [relevant] stratigraphic interval" (173)!), and this in combination with various proxies of biodiversity stress attach shifts in mercury and biodiversity with volcanic activity and detach them from the impact. "[the markers] are present at the K-Pg boundary in both sections, suggesting that the Chicxulub impact had no environmental effects on their life and preservation. Therefore, these biodiversity proxies, together with the newly found Hg anomalies, provide new and promising clues..." (173).

It strikes me that the development of these novel proxies, such as measuring $\mathrm{Hg}$ against total organic carbon, is carried out against the backdrop of analysing the relationship between volcanism and the extinction. In particular, by isolating volcanic effects from other possible explanations the one-shot hypothesis leads us to consider the volcanos as hypothetical difference-makers, and this leads to the development of proxies to help bridge the gap between the hypothetical and the plausible. Carrying out such a study certainly doesn't require a one-shot hypothesis to be on the table, but I think it plausible that seeking out tests for hypotheses is an excellent way of motivating such work. Font et al. are plausibly read as in the business of developing a proxy to test one-shot hypotheses. As they say "our study supports the use of $\mathrm{Hg}$ as a valuable volcanic... indicator and highlights its importance in the Deccan-related environmental changes at the onset of the KPg mass extinction" (173-174). There are at least two epistemic goods here: first, a deeper understanding of how to identify and analyse mercury anomalies in the record; second, further empirical support for Keller's hypothesis. Considering the volcano hypothesis as a one-shot is neither necessary nor constitutive of these goods, but I think it plausible that it's being one-shot promotes those goods.

So, on this view one-shot hypotheses serve to isolate causal features and this drives us towards developing proxies in the historical record to distinguish between that cause and others. It strikes me that, even if Keller's strong version of the volcanism hypothesis is ultimately false, the strategic value is formidable; in testing the one-shot hypothesis, we develop tools-proxies-for further and carefully distinguishing between hypotheses. As such, they are knowledge-promoting. This point, I think, accords with Carol Cleland's insight that historical science often proceeds by generating hypotheses and hunting for further traces ("smoking guns") in order to distinguish between them (Cleland 2002). However, I think that one-shot hypotheses possess further strategic value.

To ascertain the potential explanatory power of a hypothetical differencemaker, we don't only need to establish proxies to ascertain its actuality, but also to understand the dynamics of such events. For the impact hypothesis to be plausible, we don't simply want to show temporal overlap between impact and extinction, but tell a story about how the impact could have led to the extinction. This requires an understanding of the relevant causal dynamics, and I think oneshot hypotheses motivate such studies and facilitate them by isolating hypothetical difference-makers. Their mutual exclusivity and over-extension motivates a 
thorough examination of the relationship between that variable and mass-extinction scenarios. To illustrate this I'll turn to a different hypothetical differencemaker concerning the extinction: the role of terrestrial community structure. This case both motivates my point, and sets us up for the next subsection.

Although there is now general agreement that biodiversity levels leading up to the $\mathrm{K}-\mathrm{Pg}$ extinction were more-or-less steady, subtler changes in community structure could have been a crucial precursor to the extinction event. Mitchell et al. (2012) consider just such a case (see also Brusatte et al. 2015). Their worry is partly driven by the thought that any particular one-shot hypothesis looks insufficient to explain the occurrence of mass extinctions, because major volcanic events and major impacts occur with different frequencies than mass extinctions. They're interested, then, in whether changes across late Cretaceous diversity could have led to less resilience in terrestrial communities. "We compared the robustness of Campanian and Maastrichtian communities to test whether disturbances could cause extinctions more easily in Maastrichtian communities than earlier Campanian ones by using a food-web model... that is specifically designed to accommodate the uncertainties of fossil data" (18857). Such a test doesn't simply involve understanding the empirical proxies related to biodiversity, but understanding the dynamics of ecological communities: the food-web model expresses a rich conception of the relationship between community structure and resilience. For instance, one aspect of the approach is to use modelling to compare the effects of a hypothetical impact to the effects of the actual impact.

[I]n the Maastrichtian of North America not only were more taxa driven to extinction than would have been the case in a hypothetical Campanian extinction, but the guilds that were most strongly affected, and thus the clades that were hit hardest, also differed. Localities in the two intervals differ in the taxon richness of several guilds, including the very large herbivores... (18859).

Mitchell, Roopnarine and Angielczyk identify shifts in the diversity of large herbivorous dinosaurs as making a critical difference to the extinction.

This guild was highly influential because of its high number of connections in the food web: very large herbivores would have been prey of small predators (or juvenile larger predators) when young, moderately sized predators when juveniles, and top predators during adulthood... The removal of such highly connected species can have disastrous effects on communities, so the impact of the complete removal of guilds such as the very large herbivores can ripple through the food web in myriad ways (18859).

Comparing the actual mass extinction with potential extinctions is underwritten by a firm grasp of ecological dynamics, and provides insight into how ecological factors may have affected the $\mathrm{K}-\mathrm{Pg}$ scenario, as well as other events. Thus, such modelling involves the application and development of our understanding of ecological dynamics. Again the capacity of one-shot hypotheses to isolate such features, and consider their modal properties in that light, provides rich epistemic 
dividends. It turns out that the truth or otherwise of one-shot hypotheses is not what matters in their vindication: in fact, their falsity potentially promotes truth (Wimsatt 2007). A perhaps useful metaphor for seeing the importance of mutually exclusive, extended hypothetical difference-makers appeals to the role of isolation in experimentation. Experiments uncover causal relations between variables by making interventions in simple physical systems. The dependency between a particular variable and an effect is generated by holding the system fixed, and surgically and repeatedly intervening on the variable of interest in isolation (Currie and Levy 2018, Woodward 2005 and Cleland 2002). Although oneshot hypotheses do not literally enable experimentation, they do facilitate a kind of isolation, and this motivates investigations leading to rich understanding of those features and dependencies.

As we'll see in the next section, understanding both the dynamics and proxies associated with hypothetical difference-makers matters for developing richer, more complex explanations: they provide what I'll call 'explanatory resources'.

\subsection{Explanatory resources}

Since 1980 we've seen a lot of progress on understanding the dynamics and proxies of a large set of hypothetical difference-makers related to mass extinctions: relationships between global temperatures, sea-levels, oceanic acidity, atmospheric shifts, extra-terrestrial impacts, volcanism, community structures, and so on. This progress provisions paleobiologists and geologists with a rich palette of options for constructing and testing much more complex, rich explorations of the past. Hypothetical difference-makers become explanatory resources which can be integrated into larger narratives. In the last subsection I argued that one-shot hypotheses (and likely other simple narratives) scaffold investigation by acting as hypothetical difference-makers; I'll now show how one-shot hypotheses are transformed into explanatory resources, used for constructing complex narratives. ${ }^{24}$ In doing so, mutual exclusivity is jettisoned and extension is reduced.

Complex narratives are less embedded and more detailed than simple narratives, and as we've seen, I think we see a shift from simple to complex as historical reconstruction progresses. On my view, considering one-shot and other simple narratives provides investigative scaffolds for richer understanding of the dynamics and proxies associated with those hypothetical difference-makers and this underwrites the construction and testing of richer narratives. As such, they are knowledge-promoting.

As we saw above, it is striking that both large impacts and increased volcanism occur with differing frequency than mass extinctions-this in itself grants

\footnotetext{
${ }^{24}$ Ernst and Youbi (2017), drawing on improved timing estimates, provide a general model of the relationship between mass extinction events and the impressive volcanism built around large igneous provinces (such as the Siberian traps). In order to build such a model and make it at all plausible, rich understanding of both empirical proxies and the kinds of dynamics such systems exhibit are necessary. Explanatory resources generated from consideration of one-shot hypotheses, then, can also be important for building such models.
} 
plausibility to the idea that they alone are not sufficient causes (White \& Saunders 2005): we should doubt that one-shot hypotheses are likely to be true or sufficient in these circumstances. However, to build rich, complex explanations, we need sufficient explanatory resources: we need to understand the proxies and dynamics of the factors we wish to integrate. We saw an example of this in Sect. 3, where Brusatte et al. (2015) situated the impact event within other late-Cretaceous disruptions, and their possible effect upon terrestrial community structures. Such complex narratives can be imagined, of course, but for them to be empirically fruitful we need the kind of deep understanding of proxies and dynamics which investigation of one-shot hypotheses facilitates. For instance, Mitchell et al. (2012)'s application of ecological food-webs to Cretaceous communities, and Font et al. (2016)'s development of $\mathrm{Hg}$ proxies of volcanic activities, each generated explanatory resources which can then be knit together into complex narratives.

A striking example is the hypothesis that not only were the Deccan volcanoes and the Chicxulub impact each partially to blame for the extinction, but that the two were themselves linked: in particular, that the Chicxulub impact itself triggered the worst of the eruptions. ${ }^{25}$ Richards et al. (2015) suspect this idea is right. Their suspicions are motivated by two things: first, dating suggesting that the impact and the main pulse Deccan eruptions (which accounted for more than $70 \%$ of the volcanic activity) may have occurred within the same century; second, evidence that earthquakes generate eruptions. Richards et al. point out that the probability of both Deccan-style volcanism and (in particular) Chicxulub-scale impact events are very low, such that the probability of both occurring more-or-less simultaneously is vanishingly small if the events are independent. Thus, perhaps they were not independent. They ask, then, whether an impact like the Chicxulub event might be sufficient to set off the third dramatic pulse of volcanic activity. Although Richards et al. are certainly not the first to mention this possibility (indeed, it is briefly considered in Alvarez et al., 1980), only once sufficient proxies have enabled more precise timing, and sufficient understanding of both impacts and volcanism have been developed, did the more complex narrative start to bear empirical fruit. That is, a precondition for such complex narrates to be empirically fruitful - for the speculation to be productive in myself \& Sterelny's sense (2017) —is having sufficient understanding of the features cited in the narratives: and simple narratives (one-shots in particular) provide an investigative context to generate just such knowledge.

Richards et al. begin by arguing that current models do not explain the power of the Deccan's main pulse, then consider whether a large impact could have achieved this and finally link their hypothesis to a body of independent evidence. They cite a body of work linking volcanic eruptions to seismic activity: $40 \%$ of volcanic eruptions occur within a few days of a quake, and quakes clearly have other geofluidic effects (triggering geysers for instance). Although the mechanisms by which earthquakes achieve this are unknown, Manga and Brodsky (2006) examined patterns of correlations between earthquake occurrence, size and distance, and volcanic activity,

\footnotetext{
25 This is potentially an example of how linking hypotheses about the past together can further our epistemic reach, as Currie (2016) has argued.
} 
to build a model relating the two. Richards et al. draw on estimates of the earthquake potential of the Chicxulub impact, and then scale these to Manga and Brodsky's model. They thus argue that "according to historical evidence [such impact energies] appear to be large enough to trigger volcanic eruptions worldwide" (1513). Note that although this affords a triggering role to the impact, the increased volcanism throughout the late Cretaceous now plays a prominent role both as a precondition for the extinction and a star player in the extinction-causing cascade downstream of the impact.

The implication of all this is that perhaps indeed the impact provided the trigger for the extinction, but its tumultuous action was carried out via the Deccan volcanoes. That is to say, the $\mathrm{K}-\mathrm{Pg}$ extinction was a complex event not amenable to a low detail, one-shot explanation. But to get there, it seems to me, the consideration of one-shot hypotheses was critical.

\section{Conclusion}

I hope to have decoupled the justification of one-shot and other simple hypotheses from considerations of their truth or otherwise. Gerta Keller's argument against the impact hypothesis pushes against a quite powerful apparent consensus vis-à-vis the $\mathrm{K}-\mathrm{Pg}$ extinction; as such, we might wish to bet against her hypothesis. But such bets are often besides the point: developing new proxies (for instance, signalling relations between mercury and mass volcanic activity), as well as further understanding dynamics (between, say, increased volcanism and global temperature) are impressive epistemic achievements regardless. Further, such new knowledge forms the basis of richer, integrative explanations. If the consensus around impact and extinction holds, it is worth noting that the shape of the impact hypothesis has changed: it has become further situated within the specific circumstances of the late-Cretaceous; progressed from simple to complex. And this shift was facilitated, and motivated, by consideration of one-shot hypotheses.

Decoupling truth from epistemic value has insights about the kinds of strategies historical scientists adopt in uncovering the past. As Derek Turner has recently stressed, being a palaeontologist is not simply about making retrodictions: one must also make predictions about which research avenues will be fruitful (Turner 2016). In understanding those strategies we must include not only epistemic ends but strategic goods as well. The importance of such features, it seems to me, itself motivates a broader conception of epistemology: strategic goods are, I think, epistemic goods properly speaking.

There are pressing issues that I have left unexplored. For one thing, what propositional attitude ought we, or scientists, adopt towards one-shot hypotheses? Should we believe them or not? And further, by what mechanisms are oneshot hypotheses productive, when they are? Instead of taking scientists examining one-shot hypotheses to be seriously considering-being realists about—such hypotheses, we could interpret them as generating and testing hypothetical difference-makers. That is, one-shot hypotheses might be epistemically acceptable, but not belief-worthy (Potochnik 2017). Having said this, it might be that, 
psychologically speaking, scientists in fact believing one-shot hypotheses plays a crucial role in motivating the kinds of benefits I've highlighted here. For instance, stubbornness might be an important quality for pushing against consensus as Keller does, and this might psychologically require realism about one-shot hypotheses.

That is, psychological belief might be part of the mechanisms by which oneshot hypotheses provide their epistemic goods, and I've been largely silent about mechanisms. For instance, such hypotheses are sexy, and this may aid in publication, funding, and dissemination. Given science's incentive structure, chasing one-shot hypotheses might be a good strategy. In those circumstances, we might agree that in principle believing or otherwise in one-shot hypotheses is not the point, but that in practice the motivation of belief is important. An anonymous referee makes the fascinating suggestion that the preference might be due to scientists' possessing a simplistic, hypothetico-deductive model of scientific method, and this leads them to favour one-shots. If so, this might lead us to ask whether such philosophical views are themselves knowledge-promoting when held by scientists, and if so under which conditions. I think establishing the mechanisms through which one-shots do their work (when they do) might require fine-grained sociological investigation of scientists' behaviours.

For another thing, I haven't discussed when one-shot (or simple) hypotheses go wrong. If Keller is right, for instance, our commitment to the impact hypothesis has been unproductive; our biases towards psychologically satisfying explanations might lead us to miss fruitful research avenues. I take these worries seriously, but my task in this paper-articulating the positive epistemic value such hypothesizing in paleobiology might generate-is a valuable part of the question of pursuitability.

However you want to jump on such questions, I take myself to have provided a kind of epistemic vindication for a provisional assumption or preference in paleobiology favouring one-shot hypotheses. I want to note two lessons in closing. First, if one-shot hypotheses are primarily valuable for providing hypothetical differencemakers, and thus providing explanatory resources, then we might think that consensuses forming around such hypotheses are problematic. Their function is to promote productive investigation, not get things right. As such, it is plausible that a diversity of one-shots is desired. My view, then, I think promotes certain forms of pluralism (similar to, say Chang 2012). Second, I think there is a more general lesson here for normative examinations and critiques of scientific practices. In addition to simply asking after the direct-intrinsic_epistemic value of some practice, whether it is knowledge-tracking, we should also ask to what extent those practices have strategic value. How do they, say, shape epistemic communities towards productive speculation? Consideration of such questions, I think, leads to a richer and more explanatory philosophy of science.

Acknowledgements I'd like to thank Derek Turner, Elizabeth Jones, Kate MacCord and Karoliina Pulkkinen and two anonymous referees for insightful feedback on drafts. I'd also like to thank audiences at the 2018 iHPS conference at UCL, the Philosophy Departments at the University of Helsinki and UC Louvain for discussion. Some of the research for this paper was funded by a Grant from the World Templeton Charity Foundation. 
Open Access This article is distributed under the terms of the Creative Commons Attribution 4.0 International License (http://creativecommons.org/licenses/by/4.0/), which permits unrestricted use, distribution, and reproduction in any medium, provided you give appropriate credit to the original author(s) and the source, provide a link to the Creative Commons license, and indicate if changes were made.

\section{Bibliography}

Alvarez, L. W., Alvarez, W., Asaro, F., \& Michel, H. V. (1980). Extraterrestrial cause for the CretaceousTertiary extinction. Science, 208(4448), 1095-1108.

Archibald, J. D., Clemens, W. A., Padian, K., Rowe, T., Macleod, N., Barrett, P. M., et al. (2010). Cretaceous extinctions: multiple causes. Science, 328(5981), 973.

Beatty, J. (1995). The evolutionary contingency thesis. Concepts, theories, and rationality in the biological sciences, $45,81$.

Berner, R. A., VandenBrooks, J. M., \& Ward, P. D. (2007). Oxygen and evolution. Science, 316(5824), 557-558.

Brusatte, S. L., Butler, R. J., Barrett, P. M., Carrano, M. T., Evans, D. C., Lloyd, G. T., et al. (2015). The extinction of the dinosaurs. Biological Reviews, 90(2), 628-642.

Bunge, M. (1962). The complexity of simplicity. Journal of Philosophy, 59, 113-134.

Chang, H. (2012). Is water H2O?: evidence, realism and pluralism (Vol. 293). Berlin: Springer.

Churchland, P. M. (1982). The anti-realist epistemology of van Fraassen's the scientific image. Pacific Philosophical Quarterly, 63(3), 226-235.

Cleland, C. E. (2002). Methodological and epistemic differences between historical science and experimental science. Philosophy of Science, 69(3), 447-451.

Cleland, C. E. (2011). Prediction and explanation in historical natural science. The British Journal for the Philosophy of Science, 62(3), 551-582.

Cleland, C. E. (2013). Common cause explanation and the search for a smoking gun. Geological Society of America Special Papers, 502, 1-9.

Courtillot, Vincent. (1990). A volcanic eruption. Scientific American, 263, 85-92.

Currie, A. M. (2014). Narratives, mechanisms and progress in historical science. Synthese, 191(6), 1163-1183.

Currie, A. (2015a). Philosophy of science and the curse of the case study. In C. Daly (Ed.), The Palgrave handbook of philosophical methods (pp. 553-572). Palgrave Macmillan, London.

Currie, A. (2015b). Marsupial lions and methodological omnivory: function, success and reconstruction in paleobiology. Biology \& Philosophy, 30(2), 187-209.

Currie, A. (2016). Hot-blooded gluttons: dependency, coherence, and method in the historical sciences. The British Journal for the Philosophy of Science, 68(4), 929-952.

Currie, A. (2018a). Bottled understanding: the role of lab-work in ecology. British Journal for the Philosophy of Science. https://doi.org/10.1093/bjps/axy047

Currie, A. (2018b). Rock, bone, and ruin: An optimist's guide to the historical sciences. Cambridge: MIT Press.

Currie, A., \& Levy, A. (2018). Why experiments matter. Inquiry. https://doi.org/10.1080/00201 74X.2018.1533883

Currie, A., \& Sterelny, K. (2017). In defence of story-telling. Studies in History and Philosophy of Science Part A, 62, 14-21.

Currie, A., \& Walsh, K. (2019). Frameworks for historians and philosophers. HOPOS. https://doi. org/10.1086/699797

Dunbar, R. I. (2009). The social brain hypothesis and its implications for social evolution. Annals of Human Biology, 36(5), 562-572.

Elgin, C. (2007). Understanding and the facts. Philosophical Studies, 132(1), 33-42.

Elgin, C. Z. (2017). True enough. Cambridge: MIT Press.

Ernst, R. E., \& Youbi, N. (2017). How large igneous provinces affect global climate, sometimes cause mass extinctions, and represent natural markers in the geological record. Palaeogeography, Palaeoclimatology, Palaeoecology, 478, 30-52.

Font, E., Adatte, T., Sial, A. N., Drude de Lacerda, L., Keller, G., \& Punekar, J. (2016). Mercury anomaly, Deccan volcanism, and the end-Cretaceous mass extinction. Geology, 44(2), 171-174. 
Goodman, N. (1968). Safety, Strength, Simplicity. In D. H. Nidditch (Ed.), The philosophy of science (pp. 150-151). London: Oxford University Press.

Godfrey-Smith, P. (2001). Three kinds of adaptationism. In S. H. Orzack \& E. Sober (Eds.), Adaptationism and optimality (pp. 335-357). Cambridge: Cambridge University Press.

Kareiva, P., \& Carranza, V. (2018). Existential risk due to ecosystem collapse: nature strikes back. Futures, 102, 39-50.

Keller, G. (2014). Deccan volcanism, the Chicxulub impact, and the end-Cretaceous mass extinction: coincidence? Cause and effect. Geological Society of America Special Papers, 505, 57-89.

Kuhn, T. S. (1977). Objectivity, value judgement, and theory choice, the essential tension (pp. 320-339). Chicago: The University of Chicago Press.

Lewis, D. (1986). On the plurality of worlds. London, 5, 221-236.

Lipton, P. (1990). Contrastive explanation. Royal Institute of Philosophy Supplements, 27, 247-266.

Lipton, P. (1993). Is the best good enough? Proceedings of the Aristotelian Society, 93/2: 89-104. Reprinted in Papineau, D (ed.) (1996), The philosophy of science. New York: Oxford University Press: 93-106.

Liu, H. Y., Lauta, K. C., \& Maas, M. M. (2018). Governing boring apocalypses: a new typology of existential vulnerabilities and exposures for existential risk research. Futures, 102, 6-19.

Longino, H. E. (1990). Science as social knowledge: values and objectivity in scientific inquiry. Princeton: Princeton University Press.

Manga, M., \& Brodsky, E. (2006). Seismic triggering of eruptions in the far field: Volcanoes and geysers. Annual Review of Earth and Planetary Sciences, 34, 263-291.

McConwell, A. (2019). Contingency's causality and structural diversity: productive and destructive aspects of contingency. Biology \& Philosophy.

Mitchell, J. S., Roopnarine, P. D., \& Angielczyk, K. D. (2012). Late Cretaceous restructuring of terrestrial communities facilitated the end-Cretaceous mass extinction in North America. Proceedings of the National Academy of Sciences, 109(46), 18857-18861.

Nolan, D. (1997). Quantitative Parsimony. British Journal for the Philosophy of Science, 48, 329-343.

Nyrup, R. (2018). Of water drops and atomic nuclei: analogies and pursuit worthiness in science. British Journal for Philosophy of Science. https://doi.org/10.1093/bjps/axy036

Potochnik, A. (2017). Idealization and the aims of science. Chicago: University of Chicago Press.

Prum, R. O. (1999). Development and evolutionary origin of feathers. The Journal of experimental zoology, 285(4), 291-306.

Renne, P. R., Deino, A. L., Hilgen, F. J., Kuiper, K. F., Mark, D. F., Mitchell, W. S., et al. (2013). Time scales of critical events around the Cretaceous-Paleogene boundary. Science, 339(6120), 684-687.

Richards, M. A., et al. (2015). Triggering of the largest Deccan eruptions by the Chicxulub impact. Geological Society of America Bulletin, 127(11-12), 1507-1520.

Schulte, P., Alegret, L., Arenillas, I., Arz, J. A., Barton, P. J., Bown, P. R., et al. (2010). The Chicxulub asteroid impact and mass extinction at the Cretaceous-Paleogene boundary. Science, 327(5970), 1214-1218.

Sober, E. (1991). Reconstructing the past: parsimony, evolution, and inference. Cambridge: MIT press.

Steel, Daniel. (2010). Epistemic values and the argument from inductive risk. Philosophy of Science, $77(1), 14-34$.

Sterelny, K. (1996). Explanatory pluralism in evolutionary biology. Biology and Philosophy, 11(2), 193-214.

Strevens, M. (2013). No understanding without explanation. Studies in history and philosophy of science Part A, 44(3), 510-515.

Thagard, P. R. (1978). The best explanation: criteria for theory choice. Journal of Philosophy, 75, 76-92.

Turner, D. D. (2016). A second look at the colors of the dinosaurs. Studies in History and Philosophy of Science Part A, 55, 60-68.

Walsh, K. (2018). Newton's Scaffolding: the instrumental roles of his optical hypotheses. In A. Vanzo \& P. Anstey (Eds.), Experiment, speculation and religion in early modern philosophy. London: Routledge.

Ward, P. D., Kennedy, W. J., MacLeod, K. G., \& Mount, J. F. (1991). Ammonite and inoceramid bivalve extinction patterns in Cretaceous/Tertiary boundary sections of the Biscay region (southwestern France, northern Spain). Geology, 19(12), 1181-1184.

Waters, C. K. (2007). Causes that make a difference. The Journal of Philosophy, 104(11), 551-579.

Weisberg, M. (2007). Three kinds of idealization. The journal of Philosophy, 104(12), 639-659. 
White, R. V., \& Saunders, A. D. (2005). Volcanism, impact and mass extinctions: Incredible or credible coincidences? Lithos, 79(3-4), 299-316.

Wimsatt, W. C. (2007). Re-engineering philosophy for limited beings: piecewise approximations to reality. Cambridge: Harvard University Press.

Woodward, J. (2005). Making things happen: a theory of causal explanation. Oxford: Oxford University Press.

Publisher's Note Springer Nature remains neutral with regard to jurisdictional claims in published maps and institutional affiliations. 